\title{
Interpretation of interannual variability in long-term aquatic ecological surveys
}

\author{
Cauvy-Fraunié Sophie ${ }^{1,}{ }^{*}$, Trenkel Verena ${ }^{2}$, Daufresne Martin ${ }^{3}$, Maire Anthony ${ }^{4}$, Capra Hervé ${ }^{5}$, \\ Olivier Jean-Michel ${ }^{6}$, Lobry Jérémy ${ }^{7}$, Cazelles Bernard ${ }^{8}$, Lamouroux Nicolas ${ }^{5}$
}

1 Irstea Centre de Lyon-Villeurbanne, 89723, 5 rue la doua, Villeurbanne, France

2 IFREMER - Centre de Nantes, 70611, Nantes, Pays de la Loire, France

3 Irstea Centre d'Aix-en-Provence, 84233, Aix-en-Provence, Provence-Alpes-Côte d'Azu, France

${ }^{4}$ EDF R and D Site de Chatou, 151443, Chatou, Île-de-France, France

5 Irstea Centre de Lyon-Villeurbanne, 89723, Villeurbanne, Rhône-Alpes , France

6 Université Claude Bernard Lyon 1 Faculté des Sciences et Technologies, 200932, LEHNA,

Villeurbanne, France

7 Irstea Centre de Bordeaux, 84269, Cestas, Aquitaine, France

8 ENS, 26909, Paris, Île-de-France, France

* Corresponding author :Sophie Cauvy-Fraunié, email address : sophie.cauvy-fraunie@irstea.fr

\begin{abstract}
:
Long-term ecological surveys (LTES) often exhibit strong variability among sampling dates. The use and interpretation of such interannual variability is challenging due to the combination of multiple processes involved and sampling uncertainty. Here, we analysed the interannual variability in $\sim 30$ years of 150 species-density (fish and invertebrate) and environmental-observation time series in four aquatic-systems (stream, river, estuary, and marine continental shelf) with different sampling efforts to identify the information provided by this variability. We tested, using two empirical methods, whether we could observe simultaneous fluctuation between detrended time series corresponding to widely acknowledged assumptions about aquatic population dynamics: spatial effects, cohort effects, and environmental effects. We found a low number of significant results $(36,9,0 \%$ for spatial, cohort, and environmental effects), suggesting that sampling uncertainty overrode the effects of biological processes. Our study does not question the relevance of LTES for detecting important trends, but clearly indicated that the statistical power to interpret interannual variations in aquatic-species densities is low, especially in large systems where the degree of sampling effort is always limited.
\end{abstract}

Keywords: long-term ecological surveys (LTES), aquatic species (stream -river-estuary- marine), interannual variability, symbolic analyses, sampling efficiency 


\section{Introduction}

Long-term ecological surveys (LTES) are essential to examine the dynamics of ecosystems and identify the processes involved (Hobbie et al. 2003; Magurran et al. 2010; Kuebbing et al. 2018). Indeed, LTES are key to assess ecological responses (gradual or abrupt) to slow continuous environmental changes (e.g. climatic change; Sommer 2012) and sudden infrequent disturbance events (e.g., hurricanes, fires; Scheffer et al. 2001). This is particularly relevant in the Anthropocene, in which all ecosystems are threatened by a combination of multiple stressors such as climatic shifts, over-exploitation of resources, pollution, habitat degradation, and invasion by exotic species (Dudgeon et al. 2006; Halpern et al. 2008; Tilman et al. 2017; Belliard et al. 2018). In this context, LTES are of particular interest for quantifying the ecological impacts of current environmental changes and for reliably predicting future impacts (Kuebbing et al. 2018). LTES are thus crucial to provide the knowledge necessary for developing appropriate management tools to mitigate the impacts of anthropogenic pressures on ecosystems (Geheber and Piller 2012; Robertson et al. 2012) and to evaluate the effectiveness of restoration measures (Morandi et al. 2014). Nevertheless, their establishment and maintenance remains highly challenging, partly due to their cost in a context of reduced long-term funding (Lindenmayer 2017), but also due to a bias against the publication of longterm research results in favour of short-term "newsy" articles (Kuebbing et al. 2018), and a focus on funding equipment rather than funding long-term research contracts (Lindenmayer 2018).

Beyond revealing ecological trends or abrupt shifts and associated drivers, most long-term ecological time-series exhibit strong variability among sampling dates (Knapp and Smith 2001; Kratz et al. 2003). Understanding this variability is essential to identify the processes governing population and community dynamics (Lepš et al. 2019). However, the use and interpretation of such temporal (usually annual) variability is challenging due do the combination of multiple 
processes involved and sampling uncertainty. This temporal variability might be related to temporal variability in environmental conditions (e.g., interannual variations in phytoplankton linked to nutrient concentration; Salmaso 2005; 2010), change in biomass of trophic-related species (e.g., amphipod oscillation linked to diatom biovolume; Johnson and Wiederholm 1992). Variability could be also linked to variation in data collection (changes in sampling techniques, samplers, sampling timing, sampling area; Trenkel et al. 2004), and sampling inefficiency, i.e. when the study organisms being sampled do not reflect characteristics of the whole population of interest (Peterson et al. 2004; Trenkel and Cotter 2009). Sampling inefficiency depends on sampling techniques, design, and effort but also on the study organisms' dispersal capacity and their distribution area compared to the finite study area (Koenig et al. 1996). To analyse and interpret temporal variability in LTES, two approaches could be considered: an empirical approach based only on observational data or a numerical simulation including specific hypotheses concerning population dynamics. When the underlying processes of population dynamics are well identified and sampling noise is reduced, numerical simulation can allow testing alternative hypotheses about the ecological processes driving temporal variability and the effects of sampling uncertainty (Bret et al. 2017; Rivot et al. 2004). However, in the case of LTES influenced by multiple processes and with unknown sampling noise, such as LTES in large aquatic systems (e.g., river, estuary or marine continental shelf), an empirical approach is more suitable and may help identify the most relevant ecological processes involved.

In this study, we used an empirical approach to identify and interpret the information provided by the interannual variability in a unique data set grouping four independent LTES of aquatic species in France: 1) trout populations in small streams, 2) fish populations in a large river, 3) fish and invertebrate populations in an estuary, and 4) fish and invertebrate marine populations on the continental shelf (Fig. 1). These four LTES include relatively long-term ( 
30 years) annual observations of both multiannual aquatic species density with annual reproduction cycles (with an identification of age classes) and environmental measurements at various reaches Moreover, the datasets were characterized by various degrees of sampling effort, defined here as the percentage of the study area sampled (sampled area divided by the total study area): low for the three large aquatic systems (river, estuary and marine continental shelf) and high for streams. Previous analyses of these LTES revealed trends and abrupt shifts in community composition and certain aquatic species related to environmental changes. For example, Daufresne et al. 2015 showed a positive effect of restored flows on the proportion of midstream fish in the large river; Chaalali et al. (2013) showed negative effect of water warming on shrimp reproduction in the estuary; and Poulard and Blanchard 2005 reported a positive effect of sea temperature increase on subtropical species (Table 1). Here, we did not examine trends but rather focused on understanding interannual variability and potential drivers.

We thus examined the shape of the time series after removing the long-term trend (Lepš et al. 2019) and compared the shapes among time series to identify whether we could detect similarity in shape among time series; i.e. simultaneous year-to-year fluctuations. For the four LTES, characterized by a range of sampling efforts, we tested whether we could observe simultaneous fluctuations between time series corresponding to widely acknowledged assumptions about aquatic population dynamics: 1) spatial effects, spatial correlation between densities of individuals (especially for fish juveniles) between pairs of neighbouring reaches, i.e. reaches with similar environmental conditions and close enough to allow dispersal between them 2) cohort effects, temporal correlation between the densities of juveniles and the densities of older individuals with a one-year time lag (only for fish) and 3) environmental effects, correlation between aquatic species (or guild) densities and the main environmental drivers (identified in previous studies). For spatial effect, we expected a positive association between the interannual 
111 variability of aquatic-species densities from neighbouring reaches; time series should fluctuate

112 simultaneously, rising and falling together. For cohort effects, we expected a positive 113 association between the interannual variability of fish density of juveniles at year $t$ and older 114 individuals at year $t+1$; time series of fish densities of juveniles and older individuals should 115 fluctuate together in the same direction with a one-year time lag. For environmental effects, we 116 expected a positive association between the interannual variability of environmental and 117 ecological time series when the sign of the relationship between species (or guild) densities and 118 environmental parameters was positive, and negative otherwise; time series should fluctuate 119 together in the same direction when the sign of the relationship was positive, and 120 antagonistically (one rising and the other falling at the same time) otherwise. For this, we 121 applied two empirical methods: a residual Pearson correlation analysis and a symbolic analysis 122 based on Information Theory.

\section{Methods}

\section{Data description}

\section{Trout populations in small streams}

This dataset included 5-18 years of brown trout (Salmo trutta) time series sampled between 1990 and 2014 in 42 stream reaches distributed across 23 streams in France (Fig. 1). At each stream reach $\left(\sim 100 \mathrm{~m}^{2}\right)$, trout density (number of individuals per $\mathrm{m}^{2}$ ) was estimated by counting all individuals sampled using a two-pass removal electrofishing technique, without block nets (Fig. 1). Each year, the whole reach $(\sim 100 \%$ of the study reach) was electrofished in September by various operators following the European Committee for Standardization guidelines (CEN 2003; Bret et al. 2015). Based on their size, trout individuals were separated in the field into three age classes: young-of-the-year (age-0), one-year-old fish (age-1), and 2 years and older $\left(\right.$ age- $\left.2^{+}\right)$. This dataset also included daily water temperature and flow velocity time series for 
136 effect was examined between the closest stream reaches ( $<5 \mathrm{~km}$ apart) not disconnected by 137 dams. more details on the environmental data).

\section{Fish populations in a large river}

This dataset included 18-34 years of freshwater fish time series sampled between 1979 and 2015 in six river reaches situated along the Rhône River (Fig. 1). At each river reach $\left(\sim 1 \mathrm{~km}^{2}\right)$, fish density (number of individuals per $\mathrm{m}^{2}$ ) was estimated based on electrofishing using either point abundance sampling (between 20 and 200 sampling points with an average area of $7 \mathrm{~m}^{2}$ or $32 \mathrm{~m}^{2}$ depending on the study reach) or continuous sampling along the banks during $30 \mathrm{~min}$ (Fig. 1). Each year, around $0.1 \%$ of the study reach was sampled in fall by various academic teams (see Daufresne et al. 2015; Lamouroux et al. 2015 for more details on the dataset). Based on their size, fish individuals (for each species) were separated in the field into two age classes: young-of-the-year (age-0), and one year and older (age- $\left.1^{+}\right)$. Among the 41 species sampled within the six river reaches, we removed species that occurred in less than $30 \%$ of all samples (reaches and years combined), thereby preserving 16 species. For the analysis of both spatial effect and cohort effect, we only considered, for each river reach, species occurring in more than $30 \%$ of all sampling dates (see Table S1 for the resulting number of studied species per analysis). Spatial effect was analysed for the closest river reaches ( $<35 \mathrm{~km}$ apart) with similar environment and not disconnected by dams. For the analysis of environmental effects, the 16 selected species were grouped into three guilds, according to their habitat preferences following Daufresne et al. (2015), among which we examined lithophilic, midstream (species preferring deep and fast water), and southern guilds. This dataset also included daily water temperature and discharge time series for each river reach (see Daufresne et al. 2015; Maire et al. 21019 for 


\section{Fish and invertebrate populations in an estuary}

This dataset included 24-30 years of estuarine-species time series sampled between 1979 and 2014 in four estuary reaches situated along the Gironde estuary (Fig. 1). At each estuary reach $\left(\sim 5 \mathrm{~km}^{2}\right)$, estuarine fish and invertebrate density (number of individuals per $\mathrm{m}^{3}$ ) were estimated based on point abundance sampling (three sampling points along one transect; Pasquaud et al. 2012). At the three sampling points (one close to each bank and one on the middle axis of the estuary), surface and bottom samples were taken simultaneously using, respectively, two $4.0 \times 1.0 \mathrm{~m}$ rectangular frame nets, fitted at either side of the boat, and a 2.0 $\mathrm{x} 1.2 \mathrm{~m}$ frame trawl, kept at $0.2 \mathrm{~m}$ above the bottom by skates. Sampling lasted around $7 \mathrm{~min}$ and was performed during daytime, between the mid-discharge and the slack period of high tide, with the gear being towed against the current (Fig. 1). Each year, around $0.01 \%$ of the study reach was sampled every month by academic teams (see Lobry et al. 2006 for more details on the dataset). For each species, we calculated a mean autumn density by averaging the densities of the September, October, and November samples. Based on their size, fish individuals (for each species) were separated in the field into two age classes: young-of-theyear (age-0), and one year and older $\left(\right.$ age- $\left.1^{+}\right)$. Among the 59 species sampled within the four estuary reaches, we removed species that occurred in less than $30 \%$ of all samples (reaches and years combined), thereby preserving 16 species. For the analysis of both spatial and cohort effects, we only considered, for each estuary reach, species occurring in more than $30 \%$ of all sampling dates (see Table S1 for the resulting number of studied estuarine species per analyses). Spatial effect was examined between each pair of the four estuary reaches ( $<20 \mathrm{~km}$ apart). For the analysis of environmental effects, the 16 selected species were grouped into four guilds, according to their habitat preference following Lobry et al. (2006), among which we examined freshwater and marine guilds. This dataset also included daily water temperature, salinity, and 
185 discharge time series for each estuary reach (see Béguer et al. 2012 for more details on the 186 environmental data).

187

\section{Marine fish and invertebrate populations on continental shelf}

This dataset included 26 years of marine-species time series sampled between 1987 and 2014 on the eastern continental shelf of the Bay of Biscay (Fig. 1). The study area extended from $47^{\circ} 53^{\prime} 12.01^{\prime \prime} \mathrm{N}-5^{\circ} 38^{\prime} 35.99^{\prime \prime} \mathrm{O}$ to $43^{\circ} 41^{\prime} 15.00^{\prime \prime} \mathrm{N}-1^{\circ} 13^{\prime} 14.99^{\prime \prime} \mathrm{O}$, covering around 75,574 $\mathrm{km}^{2}$ between 15 and $600 \mathrm{~m}$ depth. Fish and invertebrate density (number of individuals per $\mathrm{km}^{2}$ ) and biomass $\left(\mathrm{kg}\right.$ per $\mathrm{km}^{2}$ ) were estimated based on a stratified groundfish survey, using a 36/47 GOV trawl with a $20 \mathrm{~mm}$ mesh codend liner. Each year, between 56 and 154 hauls spread over the study area (30 min samples at a towing speed of 4 knots), i.e. around $0.007 \%$ of the study area, were collected in November by Ifremer (see Poulard and Trenkel 2007 for more details on the dataset; EVHOE survey, Fig. 1). We computed density and biomass time series of the entire Bay of Biscay by averaging across all hauls. Among the 296 marine species sampled including both fish and invertebrates, we conserved only 32 species, i.e. the species occurring at more than $30 \%$ of all sampling dates. For the analysis of environmental effects, the marine selected species were separated into three functional groups according to their biogeographical affinity (temperature preference) following Quéro (1984), among which we examined boreal and subtropical groups. This dataset also included daily sea surface temperature and annual fishing pressure time series, estimated using commercial catch data obtained from the data base held by the International Council for the Exploration of the Sea (http://www.ices.dk/marinedata/dataset-collections/Pages/Fish-catch-and-stock-assessment.aspx). For the analysis of spatial effect, as the environmental fluctuations were relatively homogeneous within the Bay of Biscay and most studied marine species exhibit large scale dispersal, we split the Bay of Biscay into two zones (northern and southern) separated perpendicularly to the coast to display 
210 similar bathymetric features (Poulard and Blanchard 2015). For both zones, we computed

marine species density time series by averaging the densities recorded in all hauls from each zone (equivalent to reach in the three other LTES). Note that zone limits varied among species according to their spatial distribution to maintain a similar number of occurrences in each zone (see Fig. S1 for the zone delimitation by species).

\section{Data analyses}

We used two different methods to examine the existence of environmental effects, cohort effects, and spatial effects in the detrended time series. The first method (described below) consisted in describing the rhythm of each time series using symbolic transformation (Fig. 2 a) and techniques from Information Theory, and quantifying the association between the rhythms of the different time series, i.e. the degree to which time series tended to oscillate together, rising and falling with the same frequency (Cazelles 2004; Descamps et al. 2010). Previous studies already tested the application of this method on ecological data, compared their results with cross-correlation techniques, and concluded this method improved the detection of weak relationships between time series, even short ones and in the presence of noise (Cazelles 2003; 2004). We compared the results of this method with a second more conventional approach, which consisted in fitting a LOESS model to each time series and then calculating the Pearson correlation among detrended LOESS residuals (linear model, Fig. 2 b).

\section{Symbolic transformation}

To describe the rhythm of continuous time series, we discretized them into a sequence of a finite number of symbols (Cazelles 2004). As our objective was to identify the main drivers of interannual variability in ecological time series, we used a simple discretization based on three symbols ("Flat", "Increase", and "Decrease") reflecting changes between consecutive values 
235 (Fig. 2 a). Therefore, continuous time series $X$ of length $n$ were transformed into discrete 236 sequences $S$ of length $n$-1. First, for each species, guild or environmental parameter, we 237 computed the series $\Delta$ of length $n-1$ defined as $\Delta_{t}=X_{t}-X_{t-1}$, and computed two thresholds $I$ (for 238 increase) and $D$ (for decrease) calculated as the standard deviation of positive values of $\Delta$, and 239 the standard deviation of negative values of $\Delta$, respectively.

240 Then, given a time series $X$, and the corresponding thresholds $I$ and $D$ :

241 if $X_{t-1}<X_{t}$ and $X_{t}-X_{t-1}>I, S_{t}$ was coded 'Increase'

242 if $X_{t-1}>X_{t}$ and $\left|X_{t}-X_{t-1}\right|>D, S_{t}$ was coded 'Decrease'

243 if $\left|X_{t}-X_{t-1}\right|<D$ or $\left|X_{t}-X_{t-1}\right|<I, S_{t}$ was coded 'Flat'.

\section{Mutual information}

To quantify the degree of association between two time series, we calculated the mutual 247 information between the corresponding symbolic sequences (Pompe 1993; Prichard and Theiler

$I_{S 1 S 2}=H_{S 1}+H_{S 2}-H_{S 1 S 2}$

250 where $H_{S 1}$ and $H_{S 2}$ are the entropy of the symbolic sequences $S 1$ and $S 2$, and $H_{S I S 2}$ is their joint entropy. The entropy of a symbolic sequence $\mathrm{S}$ is defined as:

$H_{S}=-\sum_{i=1}^{k} P\left(S_{i}\right) \log \left(P\left(S_{i}\right)\right)$

253 where $P\left(S_{i}\right)$ is the probability of observing the symbol $S_{i} \in$ ("Increase", "Decrease", "Flat"), estimated as the proportion of the symbol in the sequence, and $k$ is the number of different symbols in the sequence ( $k=3$ in our case). The joint entropy $H_{S I S 2}$ between two symbolic sequences $S 1$ and $S 2$ is defined as:

$H_{S 1 S 2}=-\sum_{i=1}^{k} \sum_{j=1}^{k} P\left(S 1_{i}, S 2_{j}\right) \log \left(P\left(S 1_{i}, S 2_{j}\right)\right)$ 
258 where $P\left(S 1_{i}, S 2_{j}\right)$ is the probability of observing simultaneously the symbols $S 1_{i}$ and $S 2_{j}$, 259 estimated as the proportion of pairs $\left(S 1_{i}, S 2_{j}\right)$ observed in the sequence.

\section{Statistical significance level}

To quantify the statistical significance of this measure of common information between two time series, we compared the observed mutual information with those obtained with $n=$ 1000 couples of randomly-generated time series (Cazelles 2004). These randomly-generated time series were built under the null hypothesis of no association between two observed time series. The randomly-generated time series $Z$ were obtained by resampling the observed time series based on a Markov process scheme that preserved the short-term temporal correlations of the series (Cazelles et al. 2014). The randomly-generated time series were thus computed in the following way (Cazelles and Stone 2003; Descamps et al. 2010):

1. A frequency histogram with $n_{b}$ equal-sized intervals was created from the values of the observed time series $X$ to estimate its distribution $\left(n_{b}=3\right.$ for time series $<30$ years);

2. A transition matrix describing the time evolution of the series was created based on the frequencies of the data contained within each interval. The transition matrix gives the probability of moving from values that are within interval $b_{i}$ at time $t$ to values that are within interval $b_{j}$ at time $t+1$;

3. An initial value $Z_{0}$ was randomly selected from the observed time series $X$;

4. To determine $Z_{t+1}$, we randomly selected the interval $b_{j}$ to which $Z_{t+1}$ belonged based on the interval $b_{i}$ of $Z_{t}$, and the probabilities from the transition matrix. The value of $Z_{t+1}$ was then randomly selected among all the elements of interval $b_{j}$;

5. The previous step was iterated to obtain a randomly-generated time series $Z$ of the same length as the observed time series $X$. 
We then transformed the 1000 randomly-generated time series $Z$ into 1000 randomlygenerated symbolic sequences, and computed the distribution of the 1000 randomly-generated mutual information values under the Null hypothesis of independence. We then compared the mutual information of the observed time series $\left(I_{o b s}\right)$ with the 95th percentiles of the distribution of the 1000 randomly-generated mutual information $\left(I_{\text {sur }}\right)$. We determined a p-value for the association using a procedure based on ranks; i.e. p-value was defined as 1 minus the proportion of randomly-generated mutual information values exceeded by the observed mutual information value (the rank of $I_{o b s}$ relative to all randomly-generated mutual information values). All analyses were performed in R using the package synchrony and infotheo.

Mutual information allowed quantifying the degree of association between two time series, but without any assumption regarding the sign of the relationship between the two time series. information corresponded to our ecological hypotheses. Similarly, we verified whether the signs of the linear models between residuals corresponded to our ecological hypotheses (see the hypotheses section and Table 1).

For comparative purposes, all ecological time series were standardized by dividing all values by the respective mean prior to symbolic transformation. For each dataset, our hypotheses were generic across all reaches for both environmental and cohort effects, and across all pairs of neighbouring reaches for spatial effects. For example, for a given species, a cohort effect should occur at all reaches. To increase the statistical power of our tests for shorter time series, we concatenated, separately for each dataset, the time series of all reaches (for the Stream, River and Estuary datasets) to test both cohort and environmental effects; and we concatenated the symbolic sequences of all pairs of neighbouring reaches for the Stream and River datasets to test spatial effect (see the description of hypotheses for details). Note that randomly-generated time series were independently computed for each reach, independently 
transformed into randomly-generated symbolic sequences, and concatenated afterwards. For both spatial and environmental effects, association between time series was tested with no time lag, except for one hypothesis for the Marine dataset (see the hypotheses description and Table 1). In our analyses, significance thresholds were not corrected for multiple tests. Instead, we considered the number of positive tests as evidence for the validity of the tested hypothesis. In results, we provided $I_{o b s}-I_{s u r}$ and the associated P-value for the symbolic analysis and $\mathrm{R}^{2}$ and the P-value for the residual approach.

\section{Description of hypotheses}

\section{Trout populations in small streams}

We tested spatial, cohort, and environmental effects for the trout populations. For the spatial effect, we concatenated the time series of age- 0 trout density of all pairs of neighbouring reaches. For cohort and environmental effects, we concatenated all (42 reaches) time series of trout density (for both age- 0 and age-1) and environmental conditions. For environmental effect, we expected annual median of mean-daily water-temperature and age- 0 trout-density time series to fluctuate simultaneously in the same direction, while annual median of mean-daily water-temperature and age-1 trout-density time series, and flow velocity during emergence period and age-0 trout-density time series should fluctuate antagonistically (Table 1).

Fish populations in a large river

We tested spatial, cohort, and environmental effects for various fish populations. For the spatial effect, we concatenated the time series of age- 0 fish density for six species (Table $\mathrm{S} 1$ ) of all pairs of neighbouring reaches. For cohort effect, we concatenated all (six reaches) time series of age- 0 and age- $1^{+}$fish density for 16 species (Table S1). For environmental effect, we concatenated all time series of age- 0 fish, age-0 lithophilic-fish, southern-fish, midstream-fish densities, and environmental conditions. We expected the time series of the number of days with high flows during cyprinid reproductive period to fluctuate antagonistically with age-0 
332 fish and age-0 lithophilic-fish densities (Table 1). We expected southern-fish densities to 333 fluctuate simultaneously with time series of annual maximum of mean daily water temperature 334 and time series of mean water temperature during reproductive and growth periods. Finally, we expected midstream-fish densities and annual low-flow hydraulic conditions time series to

\section{Fish and invertebrate populations in an estuary}

We tested spatial, cohort, and environmental effects for both fish and invertebrate populations. For the spatial effect, we examined the fluctuation of density time series among each pair of estuary reaches for 13 species (Table S1). For cohort effect, we concatenated all (four reaches) time series of age- 0 and age- $1^{+}$fish density for four species (Table S1). For environmental effect, we concatenated all time series of environmental conditions, and expected mean annual salinity time series to fluctuate simultaneously with marine-species densities, and antagonistically with freshwater-species and Palaemon longirostris densities (Table 1). We also expected mean annual salinity time series to fluctuate simultaneously with Argyrosomus regius, Engraulis encrasicolus, and Dicentrarchus labrax densities, and antagonistically with Palaemon longiros densities and the percentage of shrimp ovigerous female.

\section{Marine fish and invertebrate populations on continental shelf}

For this dataset, we could only test the spatial and environmental effects for the marine populations. For the spatial effect, we examined the fluctuation of density time series between the northern and the southern zones for 32 species (Table S1, Fig. S1). For environmental effect, we expected mean annual sea surface temperature time series to fluctuate simultaneously with subtropical-species and antagonistically with boreal-species densities (Table 1). We also expected a simultaneous fluctuation between the annual commercial catch and scientific survey biomass. Finally, we expected an antagonist fluctuation between the annual commercial catch biomass at year $\mathrm{t}$ and the scientific survey biomass at year $\mathrm{t}+1$. 
Results

Trout populations in small streams

Using the residual Pearson correlation approach and the symbolic analysis, we found significant spatial effect between interannual variation of age- 0 trout densities of neighbouring

reaches (Table 2). Indeed, using the symbolic analysis, we found a significant association between variations in age- 0 trout time series; i.e. more than what could be expected by chance $\left(I_{\text {obs }}-I_{\text {sur }}=0.30, \mathrm{P}<0.001, \mathrm{n}=35\right)$, with joint probabilities contributing to the mutual

information corresponding to our hypothesis (age-0 trout density in neighbouring reaches oscillated together, rising and falling simultaneously). Similarly, using the residual analysis, we found a positive significant relationship between residuals of age- 0 in neighbouring reaches $\left(\mathrm{R}^{2}\right.$ $=0.48, \mathrm{P}<0.001)$. We also found a significant cohort effect (association between variation in age-0 trout density at year $t$ and age- 1 trout density at year $t+1)$ using both methods $\left(I_{o b s}-I_{\text {sur }}\right.$ $=0.2, \mathrm{P}<0.001, \mathrm{n}=394$, using the symbolic analysis with the joint probabilities contributing to the mutual information for analogous symbols; and $\mathrm{R}^{2}=0.44, \mathrm{P}<0.001$ using the residual analysis). However, we found no significant environmental effects as interannual variations in environmental drivers were not linked with interannual variations of trout densities $\left(I_{o b s}-I_{s u r}<\right.$ 0 for the symbolic analysis, and $\mathrm{R}^{2}<0.025$ for the residual analysis, $\mathrm{n}=[405-521]$ for three environmental drivers, see table 1).

Fish populations in a large river

Among the five tests of spatial effect performed for the dominant species (Alburnus alburnus, Squalius cephalus, Rutilus rutilus, Gobio gobio, and Chondrostoma nasus), we found a significant relationship between temporal variations of age-0 densities of neighbouring reaches only for gudgeon (Gobio gobio) based on both the mutual information approach $\left(I_{o b s}\right.$ - 
382

383

384

385

386

387

388

389

390

391

392

393

394

395

396

397

398

399

400

401

402

403

404

405

406

$\left.I_{\text {sur }}=0.029, \mathrm{P}=0.023, \mathrm{n}=32\right)$ and the residuals approach $\left(\mathrm{R}^{2}=0.22, \mathrm{P}=0.04\right.$, Table 2). For the 16 tested species, we only found a significant cohort effect for pumpkinseed (Lepomis gibbosus $)$ based on both the mutual information approach $\left(I_{o b s}-I_{s u r}=0.011, \mathrm{P}=0.038, \mathrm{n}=104\right)$ and the residuals approach $\left(\mathrm{R}^{2}=0.36, \mathrm{P}<0.001\right)$. The results for the environmental effects hypotheses showed no significant associations between variations in environmental drivers and variations in guild densities with either method $\left(I_{o b s}-I_{s u r}<0, \mathrm{P}>0.05, \mathrm{n}=1130\right.$ for the symbolic analysis; $\mathrm{R}^{2}<0.2$ for the residual analysis).

\section{Fish and invertebrate populations in an estuary}

Among the 78 tests performed (13 selected species among 6 pairs of reaches), we found 28 significant spatial effects for interannual variations of age-0 densities of neighbouring reaches based on the mutual information approach $\left(I_{o b s}-I_{\text {sur }}>0, \mathrm{P}<0.05, \mathrm{n}=[24-30]\right.$, Table 2). Note that we obtained 35 significant associations, but for seven tests, the joint probabilities contributing to the mutual information did not correspond to our hypothesis of positive associations. In particular, results showed significant spatial effects among most pairs of reaches for Alosa alosa, Alosa fallax, Anguilla anguilla, and Sprattus sprattus. With the residual approach, we obtained 56 significant positive relationships $\left(\mathrm{R}^{2}>0.2, \mathrm{P}<0.05\right)$, among which 35 with $\mathrm{R}^{2}>0.4$. We found no significant cohort effect at time lag $1\left(I_{o b s}-I_{\text {sur }}<0, \mathrm{P}>0.05, \mathrm{n}\right.$ $=98$ for the symbolic analysis; $\mathrm{R}^{2}<0.2, \mathrm{P}>0.05$ for the residual analysis) and no environmental effects $\left(I_{o b s}-I_{\text {sur }}<0, \mathrm{P}>0.05, \mathrm{n}=[72-96]\right.$ for the symbolic analysis; $\mathrm{R}^{2}<0.2, \mathrm{P}>0.05$ for the residual analysis).

\section{Marine fish and invertebrate populations on continental shelf}

Among the 32 dominant species, we found 12 significant spatial effects $\left(I_{o b s}-I_{\text {sur }}>0, \mathrm{P}<\right.$ $0.05, \mathrm{n}=26$ for the symbolic analysis, Table 2). For four other species, the association was 
407

408

409

significant but the joint probabilities contributing to the mutual information did not correspond to our hypothesis. Using the residual method, we found significant positive correlations between the residuals of both zones with $\mathrm{R}^{2}$ value higher than 0.2 for 18 species, and higher than 0.4 for 10 species. We found no significant correlation between interannual variations in sea surface temperature and interannual variations in subtropical or boreal guild densities using both approaches. Among the 17 dominant commercially exploited species, we found no significant association between interannual variations in commercial catches and interannual variations scientific survey biomass at time lag 0 . In contrast, we found a significant negative relationship between the residuals of both commercial catches and scientific biomass at lag 1 for Capros aper $\left(\mathrm{R}^{2}=0.22, \mathrm{P}=0.027\right.$ for the residual analysis $)$.

\section{Discussion}

\section{A relatively low number of significant associations}

In this study, we analysed more than 150 aquatic-ecological time series from four independent datasets to examine the information provided by the short term (interannual) temporal variability in long-term aquatic ecological time series. Overall, we identified few significant associations between the interannual variability of the different time series, both environmental and ecological, and thus did not find all expected patterns resulting from population dynamics. For all datasets and using two analytical methods, we found no significant association between the short-term variations in environmental parameters and those of species or guilds densities, although we tested environmental parameters that have been previously identified as long-term drivers of aquatic population dynamics (e.g., Bret et al. 2015; Daufresne et al. 2015; Maire et al. 2019). Similarly, we found only few significant tests for cohort effects that is an association between the interannual variations in densities of juveniles and older individuals at a one-year lag: only 2 of the 21 tests performed (9\%) were significant, while 
432 cohort tracking has been commonly observed in fish populations (e.g., Cattanéo et al. 2002; 433 Lobón-Cerviá et al. 2012; Bret et al. 2015). Nevertheless, for spatial effects, among the 116 434 tests performed, $36 \%$ were significant based on the symbolic approach $(39 \%$ based on the 435 residuals approach). The higher number of significant tests for spatial effect seems consistent 436 as the densities of individuals sampled in neighbouring sites, with similar environmental 437 conditions and located close enough to allow dispersal between them, should oscillate 438 simultaneously.

Interannual variability in aquatic ecological observations due to uncertainty in density estimates

We hypothesize that the overall low number of significant results was mainly linked to uncertainty in density estimates due to high sampling inefficiency and variable bias between sampling dates; i.e. variable proportion of the population sampled on each survey. More of the population captured (the catchability or capture probability) strongly depends on sampling effort, i.e. the area (or volume) sampled compared to the area (or volume) over which the population is distributed (Hilborn and Walters 2013). This might explain why we found significant spatial effects and cohort effects for the Stream dataset for which the whole reach was sampled, while little for the other datasets for which less than $0.1 \%$ of the study area was sampled.

In addition, catchability can also vary over time and space although it is often assumed to 453 be constant (Korman and Yard 2017). Variation in catchability depends on the temporal and spatial variation in the efficiency of the sampling gear used to capture individuals, and how sampling points are distributed relative to the distribution of individuals (Trenkel and Cotter 2009). Aquatic populations are usually distributed unevenly over different habitats within the 
457

458

459

460

461

462

463

464

465

466

467

468

469

470

471

472

473

474

475

476

477

478

479

480

study area (Ahmadi-Nedushan et al. 2006; Mérigoux et al. 2009), and the spatial distribution of habitats varies over time according to environmental conditions (Korman and Campana 2009; Dunbar et al. 2012; Capra et al. 2017). Thus, catchability could also be affected by the environmental conditions prior and during the surveys. For example, previous studies showed that spatial distribution of aquatic organisms was influenced by high wind velocity and associated marine currents in the ocean (Poulard and Trenkel 2007), high turbidity in rivers as the associated reduction in predation risk modified fish behaviour (Dodrill et al. 2016; Ward et al. 2016) or changes in flow and associated modifications in the proportion and spatial distribution of habitats (Girard et al. 2014). These environmental conditions could have also affected the sampling capacity; e.g., high wind velocity modifies ship motion and trawl geometry (Poulard and Trenkel 2007), and high discharge increases the size of the study area (or volume), and consequently reduces sampling effort.

Moreover, catchability strongly depends on species traits and dispersal capacity (Trenkel and Cotter 2009). In particular, many aquatic species are gregarious (e.g., especially cyprinid species as Alburnus alburnus, Chondrostoma nasus; Vaudor et al. 2011), thereby not evenly distributed over the study area (spatial aggregation). Spatial distribution and behaviour of aquatic species can also vary with age and size; e.g. larger fish individuals are often distributed at greater depths and further from the shore compared to smaller individuals (Vehanen et al. 1999; Woillez et al. 2007). This variation of catchability with age and size might explain the low number of significant cohort effect detected. The efficiency of a sampling design (gear, timing, spatial distribution of effort) to capture individuals also varies with organism sizes and ages (Borgstroem and Skaala 1993; Korman et al. 2009). For example, the EVHOE survey (Marine dataset) was designed for catching young (small) organisms and hence was less reliable for estimating the density of larger individuals (Trenkel and Cotter 2009). This might explain 
481 why we found almost no significant association between scientific and commercial catch biomass as commercial fishing mainly targeted larger fish.

\section{Complex interacting processes prevent the understanding of population dynamics at the} annual time scale, even using 30-years of annual surveys

In addition to the uncertainty in density estimates, there are additional explanations for the overall low number of significant results. First, the lack of significant environmental effects might be because the environmental drivers selected for this study were not appropriate to explain the observed interannual variations although relevant for long-term trends, e.g., significant increase in southern fish density with global warming (Daufresne et al. 2015), and decrease in shrimp density with estuary salinization (Béguer et al. 2012). Moreover, the mechanisms driving interannual variations were probably more complex than those driving long-term trends and might involve a combination of interacting environmental parameters (e.g., substrate quality and clogging, temperature rapid variations, short-term flow variations) at different phases of the life cycle, in particular during the first developmental stages of larvae (Schiemer et al. 2003) and recruitment of juvenile fish (Myers 1998; Grenouillet et al. 2001) but also during the period of reproduction and incubation (Korman et al. 2011). Second, the lack of consistency between the densities of juveniles and older individuals the following year might be due to high levels of dispersion, and/or high levels of mortality, linked to unknown or unmeasured environmental drivers, biotic interactions between and within species (predation, competition, facilitation) or endogenous regulatory processes such as density-dependent regulation (Grenouillet et al. 2001; Daufresne and Renault 2006; Lobón-Cerviá 2013). The lack of significant cohort effects could also be due to an inappropriate assignment of age classes. For both River and Estuary datasets, and for long-lived fish, the age class age- $1^{+}$aggregated various cohorts, potentially affected by different environmental conditions. Third, non- 
506

507

508

509

510

511

512

513

514

515

516

517

518

519

520

521

522

523

524

525

526

527

528

529

530

significant spatial effect tests could be also due to the definition of neighbouring reaches, probably not similar and/or close enough to host the same population. Indeed, for the Estuary dataset, we found more significant results among the closest stations $(<5 \mathrm{~km})$, than among the most distant ones $(>20 \mathrm{~km})$. Similarly, Bret et al. (2015) found a decrease in spatial effect among age- 0 trout densities with increasing distance between streams.

\section{Methodological limitations}

We could also question the relevance of symbolic analyses to assess the relationships between the interannual variability in environmental and ecological time series, as well as the relevance of the selected rules at the different steps of the analysis (i.e. symbolic transformation and statistical significance level). However, we repeated our analyses using different number of symbols (from 3 to 5), different threshold values (I and D, see methods), different transformation rules (coding peaks and troughs instead of increases and decreases, Cazelles et al. 2004; or coding low, medium, and high density values); and using different procedures for randomly-generated time series computation (e.g. preserving or not temporal dependencies; see Theiler et al. 1991). These complementary analyses led to similar conclusions (results not shown). Consistently, we obtained comparable results with the symbolic and residuals approaches, suggesting that our results are largely independent of the analytical method of our empirical approach. Besides, numerical simulations of aquatic-species density time series based on known ecological patterns, associated with tests of the statistical power of our two analytic methods to detect association between interannual variability of the different time series, could be an alternative approach. However, such numerical simulations are not straightforward, as illustrated for the River dataset by Vaudor et al. (2015), but rather require to make strong and questionable assumptions about numerous ecological patterns and processes (e.g., dispersal ability of the different species, strength and direction of environmental effects, and density- 


\begin{abstract}
531 dependent growth) and species distribution within study reaches to consider sampling 532 uncertainty (see above). Therefore, although analysis of statistical power based on numerical 533 simulations would complement our empirical approach, such analyses would be challenging 534 and complex and are out of the scope of this paper.
\end{abstract}

\title{
536 Conclusion
}

Our study clearly indicates that the statistical power to identify and interpret significant interannual variations in aquatic species densities is low, especially in large systems where a complete sampling of populations is unrealistic and sampling effort is limited. Although the significant spatial effects observed in our study suggests that interannual variations contains some valuable information of similarities in population dynamics, whose environmental drivers are probably multiple and not clearly identified yet; our results point out that moderate and/or isolated annual ecological changes cannot be revealed by the analysis of interannualvariations in such LTES.

Our study is focused on interannual variations and does not question the relevance of

LTES for detecting important trends or shifts as demonstrated in previous studies. However, interannual variability linked to sampling inefficiency lowers the statistical power to identify trends in large systems, supporting that long time series are required for detecting trends (Hatch 2003; Nicholson and Jennings 2004). Consistently, Vaudor et al. (2015) showed, when studying the effects of major flow restoration measures with the River dataset, that the probability of 551 detecting moderate changes (50-200\%) in population density after a restoration event averaged $16 \%$, compared to $61 \%$ for large changes $(500-1000 \%)$, and that the number of surveys well balanced before and after restoration increased this probability. exhaustive and specific monitoring methods, involving intensive sampling at a finer temporal 
556 scale. Alternative approaches would be to combine LTES with intensive continuous sampling

557 during specific periods corresponding to particular life stages (e.g., fish recruitment), or 558 measure population dynamic through individual tracking using telemetry devices or mark559 recapture techniques to estimate the probability of detection of species, thereby assessing the 560 observation error of the LTES for a given population (Capra et al. 2018; Radinger et al. 2019). 561 Finally, developing and improving population dynamic models, also using LTES (and 562 combining spatial replications of LTES; Clark et al. 2015) to test the relevance of simulations, 563 should also be encouraged; however, the requirement of continuous sampling and/or specific 564 experiments under controlled conditions to calibrate the model drivers should not be 565 overlooked. 


\section{Acknowledgments}

567 The present study was funded by the HYNES (Irstea - EDF R\&D) program. We thank the large 568 number of people who contributed to the data collection over the years. We thank Électricité de 569 France for their financial support, scientific help and for providing part of the data. We also 570 acknowledge the financial support and scientific help from Compagnie Nationale du Rhône, 571 the Agence de l'Eau Rhône-Méditerrannée-Corse, the Région Rhône-Alpes, the Région 572 Provence-Alpes-Cote-D'Azur, Rhône local collectivities, the EU-FEDER program, the EU 573 Data Collection Framework, and the research network LTSER-France. 


\section{References:}

575 Ahmadi-Nedushan, B., St-Hilaire, A., Bérubé, M., Robichaud, É., Thiémonge, N., and Bobée, B. 2006. A review of statistical methods for the evaluation of aquatic habitat suitability for instream flow assessment. River Research and Applications 22(5): 503-523.

578 Béguer, M., Bergé, J., Gardia-Parège, C., Beaulaton, L., Castelnaud, G., Girardin, M., and Boët,

Belliard, J., Beslagic, S., Delaigue, O., and Tales, E. 2018. Reconstructing long-term

P. 2012. Long-term changes in population dynamics of the shrimp Palaemon longirostris in the Gironde Estuary. Estuaries and coasts 35(4): 1082-1099.

trajectories of fish assemblages using historical data: the Seine River basin (France) during the last two centuries [journal article]. Environmental Science and Pollution Research 25(24): 23430-23450.

Borgstroem, R., and Skaala, Ø. 1993. Size-dependent catchability of brown trout and Atlantic salmon parr by electrofishing in a low conductivity stream. Nordic journal of freshwater research. Drottningholm 68: 14-20.

588 Bret, V., Bergerot, B., Capra, H., Gouraud, V., and Lamouroux, N. 2015. Influence of discharge, hydraulics, water temperature, and dispersal on density synchrony in brown trout populations (Salmo trutta). Canadian Journal of Fisheries and Aquatic Sciences 73(3): 319-329.

Bret, V., Capra, H., Gouraud, V., Lamouroux, N., Piffady, J., Tissot, L., and Rivot, E. 2017. Understanding inter-reach variation in brown trout (Salmo trutta) mortality rates using a hierarchical Bayesian state-space model. Canadian Journal of Fisheries and Aquatic Sciences 74(10): 1612-1627.

Capra, H., Pella, H., and Ovidio, M. 2018. Individual movements, home ranges and habitat use by native rheophilic cyprinids and non-native catfish in a large regulated river. Fisheries management and ecology 25(2): 136-149. 
599 Capra, H., Plichard, L., Bergé, J., Pella, H., Ovidio, M., McNeil, E., and Lamouroux, N. 2017. 600 Fish habitat selection in a large hydropeaking river: strong individual and temporal 601 602 603 604 605 606 607 608 variations revealed by telemetry. Science of the Total Environment 578: 109-120.

Cattanéo, F., Lamouroux, N., Breil, P., and Capra, H. 2002. The influence of hydrological and biotic processes on brown trout (Salmo trutta) population dynamics. Canadian journal of fisheries and aquatic sciences 59(1): 12-22.

Cazelles, B. 2004. Symbolic dynamics for identifying similarity between rhythms of ecological time series. Ecology Letters 7(9): 755-763.

Cazelles, B., and Stone, L. 2003. Detection of imperfect population synchrony in an uncertain world. Journal of Animal Ecology 72(6): 953-968.

Cazelles, B., Cazelles, K., and Chavez, M. 2014. Wavelet analysis in ecology and epidemiology: impact of statistical tests. Journal of the Royal Society Interface 11(91): 20130585.

Chaalali, A., Beaugrand, G., Boët, P., and Sautour, B. 2013. Climate-caused abrupt shifts in a European macrotidal estuary. Estuaries and Coasts 36(6): 1193-1205.

Clark, A.T., Ye, H., Isbell, F., Deyle, E.R., Cowles, J., Tilman, G.D., and Sugihara, G. 2015. Spatial convergent cross mapping to detect causal relationships from short time series. Ecology 96(5): 1174-1181.

Daufresne, M., and Renault, O. 2006. Population fluctuations, regulation and limitation in stream-living brown trout. Oikos 113(3): 459-468.

Daufresne, M., and Boet, P. 2007. Climate change impacts on structure and diversity of fish communities in rivers. Global Change Biology 13(12): 2467-2478.

Daufresne, M., Veslot, J., Capra, H., Carrel, G., Poirel, A., Olivier, J.M., and Lamouroux, N. 2015. Fish community dynamics (1985-2010) in multiple reaches of a large river 
subjected to flow restoration and other environmental changes. Freshwater Biology 60(6): 1176-1191.

Descamps, S., Yoccoz, N.G., Gaillard, J.M., Gilchrist, H.G., Erikstad, K.E., Hanssen, S.A., Cazelles, B., Forbes, M.R., and Bêty, J. 2010. Detecting population heterogeneity in effects of North Atlantic Oscillations on seabird body condition: get into the rhythm. Oikos 119(9): 1526-1536.

Dodrill, M.J., Yard, M.D., and Pine III, W.E. 2016. Assessing predation risks for small fish in a large river ecosystem between contrasting habitats and turbidity conditions. The American Midland Naturalist 175(2): 206-221.

Dudgeon, D., Arthington, A.H., Gessner, M.O., Kawabata, Z.I., Knowler, D.J., Leveque, C., Naiman, R.J., Prieur-Richard, A.H., Soto, D., Stiassny, M.L.J., and Sullivan, C.A. 2006. Freshwater biodiversity: importance, threats, status and conservation challenges. Biological Reviews 81(2): 163-182.

Dunbar, M., Alfredsen, K., and Harby, A. 2012. Hydraulic-habitat modelling for setting environmental river flow needs for salmonids. Fisheries Management and Ecology 19(6): 500-517.

Geheber, A.D., and Piller, K.R. 2012. Spatio-temporal patterns of fish assemblage structure in a coastal plain stream: appropriate scales reveal historic tales. Ecology of Freshwater Fish 21(4): 627-639.

Girard, V., Lamouroux, N., and Mons, R. 2014. Modeling point velocity and depth statistical distributions in steep tropical and alpine stream reaches. Water Resources Research 50(1): 427-439.

Grenouillet, G., Hugueny, B., Carrel, G., Olivier, J., and Pont, D. 2001. Large-scale synchrony and inter-annual variability in roach recruitment in the Rhône River: the relative role of climatic factors and density-dependent processes. Freshwater Biology 46(1): 11-26. 
648 Halpern, B.S., Walbridge, S., Selkoe, K.A., Kappel, C.V., Micheli, F., D'agrosa, C., Bruno, J.F., 649 Casey, K.S., Ebert, C., and Fox, H.E. 2008. A global map of human impact on marine ecosystems. Science 319(5865): 948-952.

651

652

653

654

655

656

657

658

659

660

661

662

663

664

665

666

667

668

669

670

671

672

Hatch, S.A. 2003. Statistical power for detecting trends with applications to seabird monitoring. Biological Conservation 111(3): 317-329.

Hilborn, R., and Walters, C.J. 2013. Quantitative fisheries stock assessment: choice, dynamics and uncertainty. Springer Science \& Business Media.

Hobbie, J.E., Carpenter, S.R., Grimm, N.B., Gosz, J.R., and Seastedt, T.R. 2003. The US long term ecological research program. BioScience 53(1): 21-32.

Knapp, A.K., and Smith, M.D. 2001. Variation among biomes in temporal dynamics of aboveground primary production. Science 291(5503): 481-484.

Korman, J., and Campana, S.E. 2009. Effects of hydropeaking on nearshore habitat use and growth of age- 0 rainbow trout in a large regulated river. Transactions of the American Fisheries Society 138(1): 76-87.

Korman, J., and Yard, M.D. 2017. Effects of environmental covariates and density on the catchability of fish populations and interpretation of catch per unit effort trends. Fisheries research 189: 18-34.

Korman, J., Kaplinski, M., and Melis, T.S. 2011. Effects of Fluctuating Flows and a Controlled Flood on Incubation Success and Early Survival Rates and Growth of Age-0 Rainbow Trout in a Large Regulated River. Transactions of the American Fisheries Society 140(2): 487-505.

Korman, J., Yard, M., Walters, C., and Coggins, L.G. 2009. Effects of Fish Size, Habitat, Flow, and Density on Capture Probabilities of Age-0 Rainbow Trout Estimated from Electrofishing at Discrete Sites in a Large River. Transactions of the American fisheries Society 138(1): 58-75. 
673 Kratz, T.K., Deegan, L.A., Harmon, M.E., and Lauenroth, W.K. 2003. Ecological variability in 674 space and time: Insights gained from the US LTER program. AIBS Bulletin 53(1): $57-$ 67.

676 677 678 679 680 681 682 683 684 685 686 687 688 689 690 691 692 693 694 695 696 697

Kuebbing, S.E., Reimer, A.P., Rosenthal, S.A., Feinberg, G., Leiserowitz, A., Lau, J.A., and Bradford, M.A. 2018. Long-term research in ecology and evolution: a survey of challenges and opportunities. Ecological Monographs 88(2): 245-258.

Lamouroux, N., Gore, J.A., Lepori, F., and Statzner, B. 2015. The ecological restoration of large rivers needs science-based, predictive tools meeting public expectations: an overview of the Rhône project. Freshwater Biology 60(6): 1069-1084.

Lepš, J., Götzenberger, L., Valencia, E., and de Bello, F. 2019. Accounting for long-term directional trends on year-to-year synchrony in species fluctuations. Ecography.

Lindenmayer, D. 2017a. Save Australia's ecological research. Science 357(6351): 557-557.

Lindenmayer, D. 2017b. Why is long-term ecological research and monitoring so hard to do?(And what can be done about it). Australian Zoologist. 39(4), 576-580.

Lobón-Cerviá, J., Rezende, C.F., and Castellanos, C. 2012. High species diversity and low density typify drift and benthos composition in Neotropical streams. Fundamental and Applied Limnology 181(2): 129-142.

Lobón-Cerviá, J. 2013. Recruitment and survival rate variability in fish populations: densitydependent regulation or further evidence of environmental determinants? Canadian Journal of Fisheries and Aquatic Sciences 71(2): 290-300.

Lobry, J., Lepage, M., and Rochard, E. 2006. From seasonal patterns to a reference situation in an estuarine environment: Example of the small fish and shrimp fauna of the Gironde estuary (SW France). Estuarine, Coastal and Shelf Science 70(1): 239-250.

Magurran, A.E., Baillie, S.R., Buckland, S.T., Dick, J.M., Elston, D.A., Scott, E.M., Smith, R.I., Somerfield, P.J., and Watt, A.D. 2010. Long-term datasets in biodiversity research 
698

699

700

701

702

703

704

705

706

707

708

709

710

711

712

713

714

715

716

717

and monitoring: assessing change in ecological communities through time. Trends in ecology \& evolution 25(10): 574-582.

Maire, A., Thierry, E., Viechtbauer, W., and Daufresne, M. 2019. Poleward shift in large-river fish communities detected with a novel meta-analysis framework. Freshwater Biology 64(6): 1143-1156.

Morandi, B., Piégay, H., Lamouroux, N., and Vaudor, L. 2014. How is success or failure in river restoration projects evaluated? Feedback from French restoration projects. Journal of Environmental Management 137: 178-188.

Myers, R.A. 1998. When do environment-recruitment correlations work? Reviews in Fish Biology and Fisheries 8(3): 285-305.

Nicholson, M.D., and Jennings, S. 2004. Testing candidate indicators to support ecosystembased management: the power of monitoring surveys to detect temporal trends in fish community metrics. ICES Journal of marine Science 61(1): 35-42.

Pasquaud, S., Béguer, M., Larsen, M.H., Chaalali, A., Cabral, H., and Lobry, J. 2012. Increase of marine juvenile fish abundances in the middle Gironde estuary related to warmer and more saline waters, due to global changes. Estuarine, Coastal and Shelf Science 104: 46-53.

Pella, H., Lejot, J., Lamouroux, N., and Snelder, T. 2012. The theoretical hydrographical network (RHT) for France and its environmental attributes. Géomorphologie : relief, processus, environnement (3): 317-336.

Peterson, J.T., Thurow, R.F., and Guzevich, J.W. 2004. An evaluation of multipass electrofishing for estimating the abundance of stream-dwelling salmonids. Transactions of the American Fisheries Society 133(2): 462-475.

Pompe, B. 1993. Measuring statistical dependences in a time series. Journal of Statistical Physics 73(3): 587-610. 
723 Poulard, J.-C., and Blanchard, F. 2005. The impact of climate change on the fish community

724

725

726

727

728

729

730

731

732

733

734

735

736

737

738

739

740

741

742

743

744

745

746 structure of the eastern continental shelf of the Bay of Biscay. ICES journal of Marine Science 62(7): 1436-1443.

Poulard, J.-C., and Trenkel, V.M. 2007. Do survey design and wind conditions influence survey indices? Canadian journal of fisheries and aquatic sciences 64(11): 1551-1562.

Prichard, D., and Theiler, J. 1995. Generalized redundancies for time series analysis. Physica D: Nonlinear Phenomena 84(3-4): 476-493.

Quéro, J.-C. 1984. Les poissons de mer des pêches françaises. J. Grancher.

Radinger, J., Britton, J.R., Carlson, S.M., Magurran, A.E., Alcaraz-Hernández, J.D., Almodóvar, A., Benejam, L., Fernández-Delgado, C., Nicola, G.G., and Oliva-Paterna, F.J. 2019. Effective monitoring of freshwater fish. Fish and Fisheries.

Rivot, E., Prévost, E., Parent, E., and Bagliniere, J. 2004. A Bayesian state-space modelling framework for fitting a salmon stage-structured population dynamic model to multiple time series of field data. Ecological Modelling 179(4): 463-485.

Robertson, G.P., Collins, S.L., Foster, D.R., Brokaw, N., Ducklow, H.W., Gragson, T.L., Gries, C., Hamilton, S.K., McGuire, A.D., and Moore, J.C. 2012. Long-term ecological research in a human-dominated world. BioScience 62(4): 342-353.

Salmaso, N. 2005. Effects of climatic fluctuations and vertical mixing on the interannual trophic variability of Lake Garda, Italy. Limnology and Oceanography 50(2): 553-565.

Salmaso, N. 2010. Long-term phytoplankton community changes in a deep subalpine lake: responses to nutrient availability and climatic fluctuations. Freshwater Biology 55(4): 825-846.

Scheffer, M., Carpenter, S., Foley, J.A., Folke, C., and Walker, B. 2001. Catastrophic shifts in ecosystems. Nature 413(6856): 591-596. 
747 Schiemer, F., Keckeis, H., and Kamler, E. 2002. The early life history stages of riverine fish: ecophysiological and environmental bottlenecks. Comparative Biochemistry and Physiology Part A: Molecular \& Integrative Physiology 133(3): 439-449.

Sommer, U. 2012. Plankton ecology: succession in plankton communities. Springer Science \& Business Media.

Theiler, J., Galdrikian, B., Longtin, A., Eubank, S., and Farmer, J.D. 1991. Using surrogate data to detect nonlinearity in time series. Los Alamos National Lab., NM (United States).

Tilman, D., Clark, M., Williams, D.R., Kimmel, K., Polasky, S., and Packer, C. 2017. Future threats to biodiversity and pathways to their prevention. Nature 546(7656): 73.

Trenkel, V.M., and Cotter, J. 2009. Choosing survey time series for populations as part of an ecosystem approach to fishery management. Aquatic Living Resources 22(2): 121-126.

Trenkel, V.M., Pinnegar, J.K., Rochet, M.-J., and Rackham, B.D. 2004. Different surveys provide similar pictures of trends in a marine fish community but not of individual fish populations. ICES Journal of Marine Science 61(3): 351-362.

Vaudor, L., Lamouroux, N., and Olivier, J.-M. 2011. Comparing distribution models for small samples of overdispersed counts of freshwater fish. Acta oecologica 37(3): 170-178.

Vaudor, L., Lamouroux, N., Olivier, J.M., and Forcellini, M. 2015. How sampling influences the statistical power to detect changes in abundance: an application to river restoration. Freshwater Biology 60(6): 1192-1207.

Vehanen, T., Mäki-Petäys, A., Aspi, J., and Muotka, T. 1999. Intercohort competition causes spatial segregation in brown trout in artificial streams. Journal of Fish Biology 55(1): $35-46$.

Ward, D.L., Morton-Starner, R., and Vaage, B. 2016. Effects of turbidity on predation vulnerability of juvenile humpback chub to rainbow trout and brown trout. Journal of Fish and Wildlife Management 7(1): 205-212. 
772 Williams, P.J., Hooten, M.B., Womble, J.N., Esslinger, G.G., and Bower, M.R. 2017. Monitoring dynamic spatio-temporal ecological processes optimally. arXiv preprint arXiv:1707.03047.

775 Woillez, M., Poulard, J.-C., Rivoirard, J., Petitgas, P., and Bez, N. 2007. Indices for capturing spatial patterns and their evolution in time, with application to European hake (Merluccius merluccius) in the Bay of Biscay. ICES Journal of Marine Science 64(3): $537-550$. 
779 Table 1: Summary of the hypotheses for environmental effects. This table summarize the relationship (including the sign) between

780 aquatic species (or guild) and environmental parameters observed in previous studies examining the same datasets.

\begin{tabular}{|c|c|c|c|c|}
\hline Datasets & Environmental parameters & Ecological data & $\begin{array}{l}\text { Expected } \\
\text { sign of the } \\
\text { relationship }\end{array}$ & References \\
\hline Stream & $\begin{array}{l}\text { Annual median of mean daily water temperature } \\
\text { Annual median of mean daily water temperature } \\
\text { Flow velocity during emergence period (March-April) }\end{array}$ & $\begin{array}{l}\text { age- } 0 \text { trout } d . \\
\text { age- } 1 \text { trout } d . \\
\text { age- } 0 \text { trout } d .\end{array}$ & $\begin{array}{l}+ \\
- \\
-\end{array}$ & Bret et al. 2015 \\
\hline River & $\begin{array}{l}\text { Nbr. of days with high flows during cyprinid reproductive period (March-June) } \\
\text { Nbr. of days with high flows during cyprinid reproductive period (March-June) } \\
\text { Annual maximum of mean daily water temperature } \\
\text { Mean water temperature during reproductive and growth periods (April-August) } \\
\text { Annual low-flow hydraulic conditions }\end{array}$ & $\begin{array}{l}\text { age- } 0 \text { fish } d \text {. } \\
\text { age-0 lithophilic-fish d. } \\
\text { southern-fish d. } \\
\text { southern-fish } d \text {. } \\
\text { midstream-fish d. }\end{array}$ & $\begin{array}{l}- \\
- \\
+ \\
+ \\
+\end{array}$ & $\begin{array}{l}\text { Daufresne et al. } 2015 \\
\text { Lamouroux et al. } 2015\end{array}$ \\
\hline Estuary & $\begin{array}{l}\text { Mean annual salinity } \\
\text { Mean annual salinity } \\
\text { Mean annual temperature } \\
\text { Mean annual temperature } \\
\text { Mean annual temperature } \\
\text { Mean annual temperature } \\
\text { Mean annual salinity } \\
\text { Mean spring temperature }\end{array}$ & $\begin{array}{l}\text { marine-species d. } \\
\text { freshwater-species } \mathrm{d} . \\
\text { Argyrosomus regius } \mathrm{d} . \\
\text { Engraulis encrasicolus } \mathrm{d} . \\
\text { Dicentrarchus labrax } \mathrm{d} . \\
\text { Palaemon longirostris } \mathrm{d} . \\
\text { Palaemon longirostris } \mathrm{d} . \\
\text { Shrimp reproduction } \\
\text { ovigerous female) }\end{array}$ & $\begin{array}{l}+ \\
- \\
+ \\
+ \\
+ \\
- \\
-\end{array}$ & $\begin{array}{l}\text { Béguer et al. } 2012 \\
\text { Pasquaud et al. } 2012\end{array}$ \\
\hline Marine & $\begin{array}{l}\text { Mean annual sea surface temperature } \\
\text { Mean annual sea surface temperature } \\
\text { Annual commercial catch } b \text {. (year } t \text { ) } \\
\text { Annual commercial catch } b \text {. (year } t \text { ) }\end{array}$ & $\begin{array}{l}\text { subtropical-species d. } \\
\text { boreal-species d. } \\
\text { scientific survey b. (year } \mathrm{t} \text { ) } \\
\text { scientific survey b. }(\text { year } \mathrm{t}+1) \\
\end{array}$ & $\begin{array}{l}+ \\
- \\
+ \\
-\end{array}$ & $\begin{array}{l}\text { Poulard and Blanchard } \\
2005\end{array}$ \\
\hline
\end{tabular}


782 Table 2: Summary of our results: number of significant associations per number of test performed 783 for each hypothesis and dataset. We considered a significant synchrony, for the symbolic analysis, 784 when the observed mutual information was higher than the 95th percentiles of the distribution of 785 the 1000 surrogate mutual information $\left(\mathrm{I}_{\mathrm{obs}}-\mathrm{I}_{\text {sur }}>0\right.$, ) and the joint probabilities contributing to the 786 mutual formation corresponded to our hypothesis. For the residual analysis, we considered a 787 significant synchrony when the correlation between residuals was significant $(\mathrm{P}<0.05)$ with $\mathrm{R}^{2}$ $788>0.4$, and the sign of the relationship corresponded to our hypothesis.

789

\begin{tabular}{llllllllll}
\hline & \multicolumn{2}{l}{ Spatial effects } & & \multicolumn{2}{l}{ Cohort effects } & \multicolumn{3}{c}{ Environmental effects } \\
Datasets & Symbolic & Residual & & Symbolic & Residual & \multicolumn{2}{c}{ Symbolic } & Residual \\
& & $R^{2}>0.4$ & $R^{2}>0.2$ & & $R^{2}>0.4$ & $R^{2}>0.2$ & & $R^{2}>0.4$ & $R^{2}>0.2$ \\
\hline Stream & $1 / 1$ & $1 / 1$ & $1 / 1$ & $1 / 1$ & $1 / 1$ & $1 / 1$ & $0 / 3$ & $0 / 3$ & $0 / 3$ \\
River & $1 / 5$ & $0 / 5$ & $1 / 5$ & $1 / 16$ & $0 / 16$ & $1 / 16$ & $0 / 5$ & $0 / 5$ & $0 / 5$ \\
Estuary & $28 / 78$ & $35 / 78$ & $56 / 78$ & $0 / 4$ & $0 / 4$ & $0 / 4$ & $0 / 8$ & $0 / 8$ & $0 / 8$ \\
Marine & $12 / 32$ & $10 / 32$ & $18 / 32$ & - & - & - & $0 / 36$ & $0 / 36$ & $1 / 36$ \\
\hline
\end{tabular}




\section{Figure legends:}

792 Figure 1: Site localisation and sampling methods of the four datasets: 1) Trout populations in small 793 streams (in green), 2) Fish populations in a large river (in red), 3) Fish and invertebrate populations 794 in an estuary (in purple), and 4) Marine fish and invertebrate populations on continental shelf (in 795 orange). The theoretical hydrographical network (RHT, Pella et al. 2012) was used to represented 796 the French stream network (Strahler order $>2$ ).

798 Figure 2: Illustration of the first step of both approaches used to evaluate the synchrony between 799 time series: a) the symbolic transformation, and b) the residual computation. In both panels, open 800 dots represent a standardized fish density time series. In panel a, the continuous time series is 801 transformed into a discrete sequence of three symbols (F for "Flat", I for "Increase", and D for 802 "Decrease"). This step precedes the mutual information calculation between two symbolic 803 sequences. In panel b, residuals of a LOESS model are extracted. This step precedes the linear 804 model among residuals from two time series. 


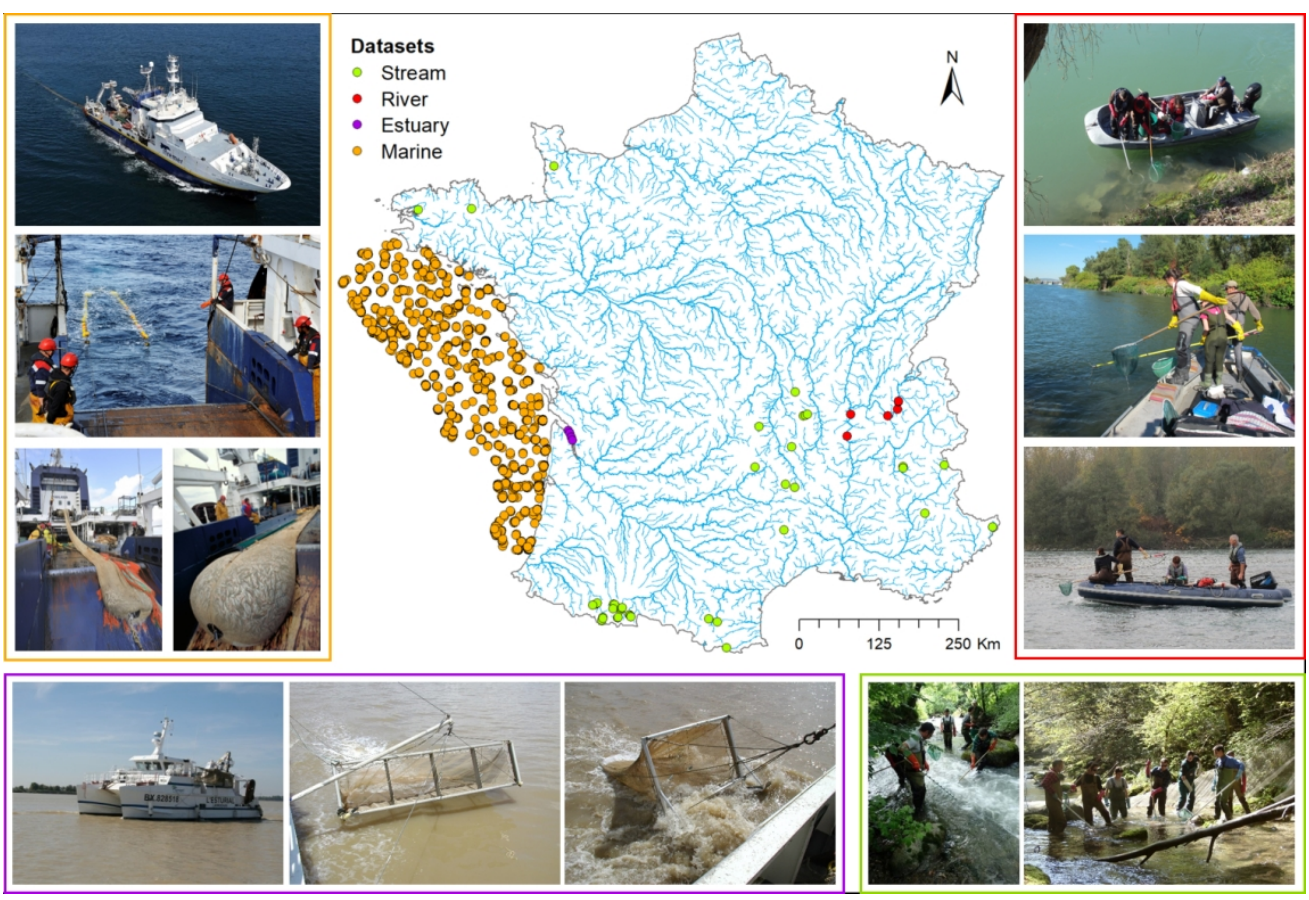



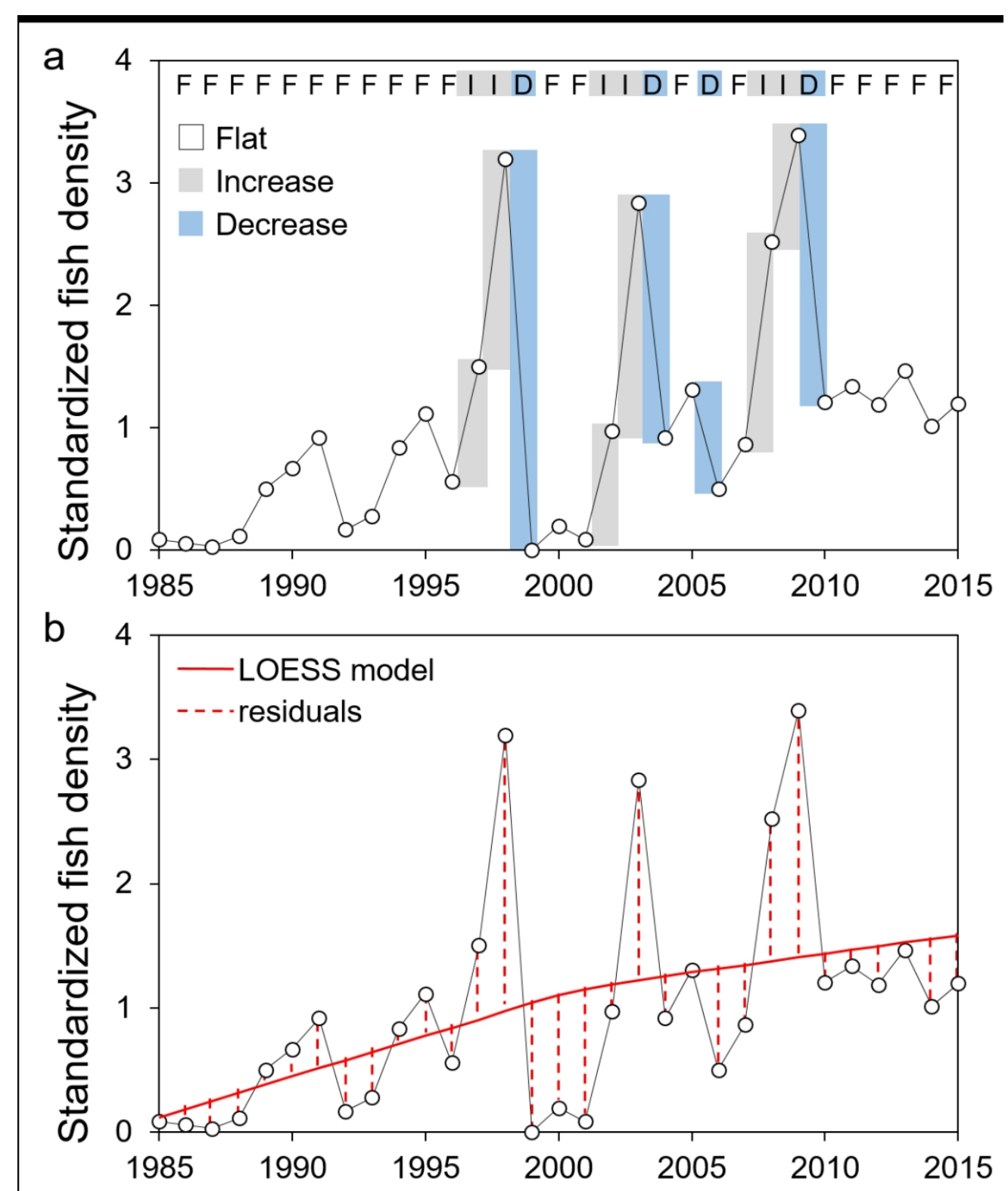